\title{
A Review of Candidate Methods for Detecting Incipient Defects Due to Aging of Installed Cables in Nuclear Power Plants
}

Frederick I. Mopsik, Edward F. Kelley and Francoise D. Martzloff

U.S. DEPARTMENT OF COMMERCE

National Bureau of Standards

Institute for Materials Science and Engineering

Center for Electronics and Electrical Engineering

Gaithersburg, MD 20899

May 1988

Contract No. NRC-FIN-D1715

Jit Vora, Contract Officer

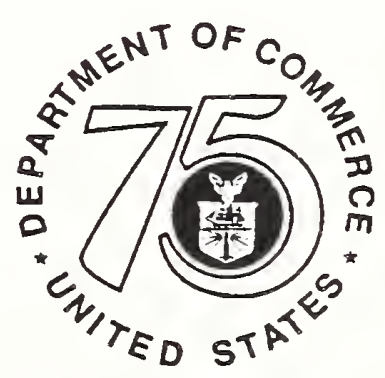

Prepared for:

75 Yours Stimulating America's Progress

Nuclear Regulatory Commission

5650 Nicholson Lane South

Rockville, MD 20852 



\section{A REVIEW OF CANDIDATE METHODS FOR DETECTING INCIPIENT DEFECTS DUE TO AGING OF INSTALLED CABLES IN NUCLEAR POWER PLANTS}

Frederick I. Mopsik, Edward F. Kelley and Francoise D. Martzloff

U.S. DEPARTMENT OF COMMERCE

National Bureau of Standards

Institute for Materials Science and Engineering

Center for Electronics and Electrical Engineering

Gaithersburg, MD 20899

May 1988

Contract No. NRC-FIN-D1715

Jit Vora, Contract Officer

Prepared for:

Nuclear Regulatory Commission

5650 Nicholson Lane South

Rockville, MD 20852

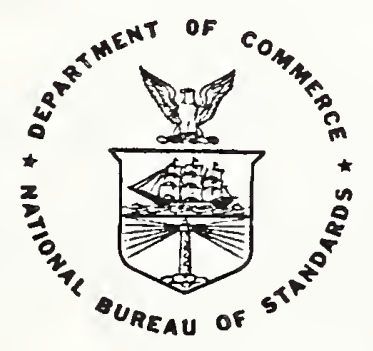

U.S. DEPARTMENT OF COMMERCE, C. William Verity, Secretary NATIONAL BUREAU OF STANDARD, Ernest Ambler, Director 



\title{
A REVIEW OF CANDIDATE METHODS FOR DETECTING INCIPIENT DEFECTS DUE TO AGING OF INSTALLED CABLES IN NUCLEAR POWER PLANTS
}

\author{
Frederick I. Mopsik, Edward F. Kelley and François D. Martzloff \\ National Bureau of Standards \\ Gaithersburg MD 20899
}

\section{ABSTRACT}

Several types of test methods have been proposed for detecting incipient defects due to aging in cable insulation systems, none offering certainty of detecting all possible types of defects. Some methods apply direct detection of a defect in the cable; other methods detect changes in electrical or non-electrical parameters from which inferences can be drawn on the integrity of the cable. The paper summarizes the first year of a program conducted at the National Bureau of Standards to assess the potential of success for in situ detection of incipient defects by the most pronising of these methods.

\section{INTRODUCTION}

Among the many components being considered for aging assessment and residual life extension of nuclear power plants, cables merit consideration because of their unique role in plant safety systems and support systems. Stresses imposed on the cables include mechanical stresses at the time of construction and installation, followed by many years of operational environment conditions. Aging takes place under the combined effects of humidity, heat, oxidation, and radiation environment associated with each cable system. And yet, under accident situations, the aged cables are expected to withstand the mechanical and environmental stresses associated with such an event and to perform their intended function. This situation, however, has not escaped the attention of system designers, plant operators and regulators. The detection of incipient defects has become a recognized subject of study. This paper presents a progress report on some of the work performed at the National Bureau of Standards (NBS) to assess applicability of known insulation test methods for in situ detection of incipient defects.*

A review of existing practices and of the literature on insulation evaluation tests shows that existing facilities depend mainly on the use of cables that have been qualified to appropriate national codes and standards prior to installation and operation. There are ongoing programs, however, for assessing aging of installed cables, but no simple method has been found for performing nondestructive in situ tests. There are many recognized tests for assessing the condition of a cable insulation but most of them are destructive and are typically performed in the laboratory on specimens that include new cables, artificially aged cables, and naturally aged cables. Tests on artificially aged cables, where the aging is accelerated by one or more environmental overstresses, are unavoidably subject to debate on the validity, conservatism, or ambiguity of the acceleration process.

* Performed under the sponsorship of USNRC Nuclear Plant Aging Research Program. 
A very important concept for in situ insulation evaluation by nondestructive test methods is that trends in test results yield much more information than absolute values obtained from single tests. Therefore, any program of insulation evaluation is likely to require establishing and updating a data base of the test results. Thus, in addition to the technical challenge of the test method itself, a significant part of the total challenge will be the logistics of managing the data base. A further challenge will be the credibility of conclusions based on small changes observed over a long period of time by tests methods that have yet to be generally accepted. One aspect of acceptability criteria is that the test methods should be simple enough to be performed by moderately qualified personnel, with a minimum of subjective interpretation of the results.

Figure 1 shows a simplified diagram illustrating the range of severity in cable defects and the types of detection methods that could be applied for detecting such defects by nondestructive in situ tests. There are two major categories of tests: (1) tests providing direct detection of single or multiple defects, and (2) tests revealing a change in the overall dielectric or mechanical characteristics of the insulation, from which inferences can be derived on the adequacy of the insulation. The methods reviewed during 1987 by the NBS multidisciplinary team fall in these two categories and will be briefly described. The plans for further assessment of promising candidate methods will also be presented, soliciting cooperation of all parties in beginning the task of correlating test results. From such a cooperative effort, tests methods could gain acceptability for demonstrating the behavior of naturally aged cables and an assessment of the residual life of cable systems.

\section{SEVERITY LOCALIZED OF DEFECTS DEFECTS \\ (DIRECT)}

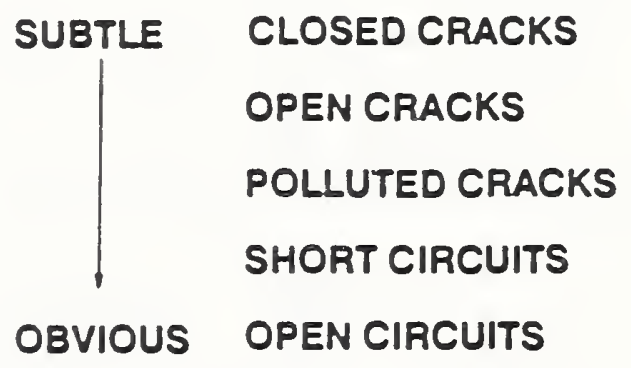

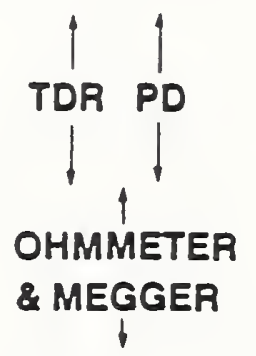

\section{GENERAL CONDITION (INFERENCES)}

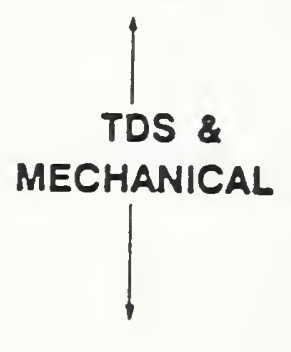

Figure 1. Range of defects and test methods

\section{DIRECT DETECTION METHODS}

Methods for the direct detection of incipient defects in the insulation are inherently based on tests assessing the electrical characteristics of the insulation and conductor system. In contrast, methods based on inferences can apply some other type of test. For instance, a mechanical test can be performed, from which inferences are drawn on the basis of prior knowledge of correlation between the observed mechanical behavior and the ultimate electrical quality of the insulation. The direct test methods reviewed by the NBS team include two basic approaches, each including two specific implementations. The first approach is time-domain reflectometry; the second is based on the detectable occurrence of partial discharges, with a possibility of combining the two approaches in a single method.

Time-Domain Reflectometry (TDR)

The basic concept of TDR consists of launching a fast-transition waveform into one end of a transmission line while the instantaneous voltage, at the same end of the line, is displayed as a function of time. Reflections caused by discontinuities in 
the impedance of the transmission path cause a voltage change which is displayed at a time corresponding to the round-trip time between the origin and the site of the discontinuity. For a given velocity of propagation, the round-trip time may be converted into the distance from the sending end of the line to the impedance discontinuity.

There are several advantages, as well as limitations, to the use of TDR techniques to determine the presence of damage or morphological changes in the insulation of a cable. The primary advantage of TDR techniques is the ability to determine the location of the damage without the removal of the cable from its installation in raceways or conduits. Additionally, since TDR techniques use low-voltage pulses, the method does not stress the cable being tested and thus avoids inducing damage resulting in subsequent cable failure. The primary disadvantage appears to be the lack of discrimination between impedance discontinuities caused by artifacts (such as splices or connectors in the cable) and significant damage to the cable caused by abrasion or cracking of the insulation.

In order to understand the capabilities and limitations of TDR techniques to detect and locate damage in the cables, two approaches were used. The first approach is experimental, using commercial TDR equipment to identify the practical limitations of reflectometry on cables containing known defects. The second approach is theoretical, modeling the cable system by computer-aided electronic circuit analysis methods. From the combination of these approaches, insight was gained into the following questions:

- What is the smallest impedance change that may be resolved by TDR methods using equipment with a given noise level and dynamic range?

- What are the limits of the electrical characteristics of the cable, such as impedance mismatch of a cable to the pulse generator, which cause attenuation and consequently will affect the defect detection capability?

- What is the resolution capability of a TDR system when a small impedance change, representing a defect, is located near a large impedance change such as is encountered in an electrical connector?

- How far can the fast-transition pulse travel in a cable before its fast transition is altered, losing its capability for fine defect resolution?

One of the fundamental limitations of the TDR method for the detection of defects in cables may be the long-term stability of a TDR system. For TDR to be useful, it will be necessary to perform differential measurements on cables, that is, measure the TDR signature of cables over a long period of time to determine the changes attributable to damage. Since the system measurment accuracy may be a major consideration for the detection and location of defects in a cable, uncertainties associated with the TDR instrumentation may limit the sensitivity of the method. Such uncertainties include noise within the instrumentation as well as noise introduced by the cable. Furthermore, major impedance changes associated with connectors can mask adjacent changes associated with incipient defects which, ironically, are most likely to be near cable connections.

For a specific cable, it is possible to use analytical techniques to predict the characteristics of a defect detectable by TDR techniques. Conversely, modeling a hypothetical defect and comparing the result of TDR simulation with an actual TDR signature can provide insights for explaining a change in TDR signature over a period of time. 
A system has been developed by EG\&G Idaho, called the Electrical Circuit Characterization And Diagnostic (ECCAD) system. This system includes TDR as well as the measurement of several other parameters under computer control. The measurements, however, cannot reveal small changes which are highly localized along the length of the circuit (such as a single crack or small abrasion in the insulation). It must be pointed out that these limitations do not mean that an ECCAD system is of little value to industry. Most of the advantages have been documented in the literature [1],[2],[3]; the limitations, however, should also be recognized.

Reliable detection of incipient defects will depend upon the sensitivity of the system and on the physical length and severity of the change of dielectric constant or loss factor of the insulation. Previous DOE-sponsored tests [4] performed at NBS demonstrated the limitations of TDR on the detection of isolated defects along shielded cables. In that study, it was shown that TDR could not be used to find a breakdown channel in a concentric-cylinder transmission line.

In considering this limitation, it must be remembered that the ECCAD system records the TDR signature in its entirety, that is, it records the signature for the entire length of the circuit tested, and at low resolution so that the entire range of the reflection coefficient can be observed (from-1 to 1). If we assume that the TDR signature is temporally digitized in 512 points with a 10 -bit resolution (0.1\%), then a $15-\mathrm{cm}$ section of cable would represent a 1 -ns duration in the TDR signature. A $100-m$ cable would display a TDR signature of about 600 ns in duration. A small defect of 1 centimeter or less in length, unless inducing greater losses, would hardly be visible even if it changed the TDR signature by 18 .

To illustrate these concerns, a simple experiment was conducted to compare the TDR signature for a fully insulated test wire against the signature for the same test wire after a piece of insulation has been removed. Small changes in the wire position produced dramatic (a few percent) changes in the TDR signature in the vicinity of the test region. Such a result alerts us to potential difficulties in taking TDR signatures on unshielded cables. If the unshielded cables were moved, the TDR signatures would be changed. Thus, if historical TDR data were taken for later reference, whenever an unshielded cable is moved in a tray of cables, it would be necessary to make a new record of all the TDR signatures affected by the move.

The conclusion of this review was that there are defects which TDR techniques at low voltage cannot successfully detect: those which cause small changes in the insulation dielectric over a small length of the circuit. One possible technique was then considered: TDR-type signatures obtained with short (less than $100 \mathrm{~ns}$ ), high-voltage pulses generating partial discharges and thus making the defect more detectable. The acronym LEPT (Low Energy Pulse Testing) was coined to emphasize the low energy aspect of the approach.

\section{Low-Energy Pulse Testing (LEPT)}

For the initial tests, it was expected that pulses with peaks of $2 \mathrm{kV}$ to $10 \mathrm{kV}$ and widths of less than 100 ns could accomplish the purpose. For reference, it should be noted that a discharge from a $1-\mathrm{nF}$ capacitor charged at $5 \mathrm{kV}$ is at the threshold of detection by human fingers - it is a less severe pulse than one experiences by touching a metal object after walking on a carpet on a dry day. This electrostatic discharge involves the human body capacitance (0.15 nF) charged as high as $15 \mathrm{kV}$. Most non-electronic equipment can survive such a discharge without difficulty.

Exploratory tests with a simple bare wire insulated from a ground plane by a thin sheet of insulating material produced detectable partial discharges for pulses as narrow as $30 \mathrm{~ns}$, at amplitudes of $2 \mathrm{kV}$. However, because the scope of this project 
does not include the development of new techniques, experiments were not conducted beyond the exploratory stage. Further exploratory development work could produce more conclusive results.

\section{Partial Discharges Detection}

Detection of partial discharges is a tool that has been widely used in the electrical industry, but the classical techniques have limitations that would make difficult their application to in situ cable tests. One of the major problems is the poor signal/noise ratio in environments other than a well-shielded high voltage laboratory. Another limitation in nondestructive tests is the permissible amount of discharge, because the discharge phenomenon could be described as consuming part of the insulation life. Consequently, the voltage at which the tests are conducted could become an issue.

Two detection methods using signal processing techniques have been described in the literature [5], [6]. The advantage of the method developed by Weeks and Steiner is that signal correlation and averaging techniques will allow detection of very small discharges, even in the presence of substantial background noise, and at relatively low voltages. We intend to explore these methods to evaluate their capability for detecting discharges originating from multiple sites in complex cable systems, and at the lowest possible voltage.

\section{METHODS BASED ON INFERENCES}

\section{Mechanical Properties}

Changes in the mechanical properties of insulating materials have been associated with changes in the electrical insulation integrity of cables, forming a useful body of knowledge which is generally accepted as a valid assessment of a particular cable [7], [8]. Testing to determine these changes includes the measurement of parameters such as tensile strength and elongation. In this form, these tests can only be destructive, and are performed in the laboratory on specimens obtained from cables removed from service.

A new method that could be applicable for in situ tests has been proposed by Toman and Gardner [9]. In this method, a test fixture is used that could be installed at accessible points of installed cables. A fixed anvil and a moving wedge produce a controlled deformation of the insulation for plotting of the stress/strain characteristic of the insulation. According to reported laboratory tests of this method, a significant correlation has been established between the results of the stress/ strain measurement and the electrical integrity of the insulation. To the extent that a test limited to the accessible points can be used to assess the overall condition of the cable, this method appears promising.

\section{Dielectric Tests}

Measuring changes of insulation resistance is a well-accepted method for assessing the quality of insulating systems. It has been used in the electrical industry for many decades, not just limited to cables. Note that it is the change, rather than the absolute value that is generally considered significant. In some instances, empirically determined thresholds are also used to signal a process of degradation beyond which reliability decreases sharply [10]. In addition to the resistance, generally determined by application of a dc test voltage of 500 or $1000 \mathrm{~V}$, or some 
other value related to the rated voltage of the equipment, the 'polarization index' is also determined. This index is the ratio of two insulation resistance values measured, for instance, after one minute and ten minutes of test voltage application. While highly empirical, this method has been found useful as a quick check to assess the insulation quality (not to detect single point defects). Because it involves the time-varying change of the dielectric material, it might have some of the elements of the much more sophisticated method of time-domain spectroscopy, discussed later in this paper.

Another well-known method, sometimes cited disparagingly, is the application of an ac test voltage at some arbitrary value above the service voltage of the system. Historically, this method has been enshrined as a 'twice rated plus one thousand' criterion, but its roots are more a demonstration of adequate clearances than adequate insulation. The inference is that if the equipment can withstand that level of overstress, sufficient margin is available to ensure reliable service. The objection is, of course, that the test can be destructive or, worse yet, pass the insulation but leave it in a weakened state compared to its state before the test. Attempts were made to limit this situation by applying the overvoltage for brief periods, from which the nickname of 'thumper' was derived. Selecting an appropriate test voltage is an exercise in brinkmanship between demonstrating sufficient margin and creating defects in the insulation. Going beyond such methods was one of the objectives of the NBS assessment program, and it is cited here only to provide a historical perspective.

\section{Time-Domain Spectroscopy (TDS)}

Time-domain spectroscopy is a relatively new technique for determination of the frequency spectrum of the dielectric loss of a material from its measured time behavior in response to a step-voltage excitation. The state-of-the-art instrument, developed before the NBS program was initiated, is described in Ref [11]. With this instrument, a precisely defined voltage step is applied to a guarded, three-terminal insulation specimen and the charge response is measured for time durations ranging from $10 \mu \mathrm{s}$ to up to $3000 \mathrm{~s}$. By conversion of the time-domain signals to frequency domain, the response of the material can be expressed over the equivalent frequency range. The resolution on loss measurement ( $\tan \delta$ ) is in the order of one part per million. This measurement is clearly a lumped circuit method in which the only geometric parameters involved are those that define a geometric capacitance. The remarkable sensitivity of the TDS method is illustrated by the measurements described in the next two sections.

The instrument is capable of detecting almost any relaxation in any polymer that falls within the instrumental frequency range, including low-loss and high-quality insulation. Its frequency range is well adapted to relaxations with time scales that are measured mechanically. The technique is not concerned with particular features along a cable but rather with the nature of the total cable insulation.

The anticipation is that environmentally-induced changes in the cable insulation will either lead to relaxations, change them. or shift their time scales. Furthermore, we assume that these changes could be used to anticipate future problems. Specifically, shifting of the loss peak corresponding to the glass-transition of a polymer would indicate possible embrittlement of the material and potential failure on flexure. These changes, however, are very material-dependent and their occurrence and effect would have to be established on a case-by-case basis. Thus, it is important to establish a catalog of materials (cables) to assess the generic applicability of the methods.

Another potential application of TDS is the measurement of the true dc conductivity of the insulation. Normally, for many polymers, this measurement is very difficult as dipolar relaxation can easily occur on the time scale of the measurement. This 
limitation is a problem with the standard ASTM method of measuring current 1 minute after application of the voltage. However, a frequency-domain analysis of the loss spectrum can determine a true conductance, even in the presence of losses.

For installed cables, we recognize several limitations. First, the cable insulation sections are effectively in parallel so that only an average quantity is measured, not a particular defective section. Second, the cables need a ground reference definition (i.e., a shield) so that the environment is not significantly included. Third, the measurement can be conducted only if the cable is disconnected from any parallel load. (The test could, however, be made on a three-phase cable with a load left connected, applying the test voltage on all three conductors together, with respect to ground.) Finally, cable length will limit the maximum frequency obtainable; however, it seems that the most interesting changes occur at the low-frequency side of the spectrum. Nevertheless, the advantages of the method appeared attractive enough to motivate several experiments, using the existing NBS instrument on specimens obtained from other parties involved in the aging assessment program. Two such measurements are reported-here.

\section{TDS measurements on naturally aged cables}

Three pieces of coaxial cable were obtained from the Shippingport nuclear power plant. Two samples were obtained from EG\&G-Idaho, expected to be a pair of the same type of cable, one having been irradiated in the harsh environment, the other as having been removed from the control room and thus not irradiated. Actually, the samples were of the same type, but from different manufacturers. This difference of manufacturer may leave a question on an observed difference between the two samples. To avoid this ambiguity, another sample was obtained after a visit to the Shippingport site. This third sample was taken from the control room, where a more recent addition had been installed, and was of the same manufacturer as the sample removed from the containment.

The cable that was exposed to radiation environment could be readily identified from the others. The outer PVC jacket on the exposed cable had a few cracks perpendicular to the cable axis and was much stiffer and harder to cut. The mold marks from the braid were not as prominent, indicating that shrinkage had occurred. The polyethylene dielectric was yellow, as contrasted to the white color it normally has in new cable and in the samples that were not exposed to radiation.

The three samples were tested at 30 and $50^{\circ} \mathrm{C}$ with frequency coverage from $10^{-4}$ to $6 \times 10^{4} \mathrm{~Hz}$. Because of the small sample capacitance and low loss levels, the data were taken as a four-shot average to minimize noise. At $30^{\circ} \mathrm{C}$, the recordings from all samples were similar, but at $50^{\circ} \mathrm{C}$, the irradiated sample clearly showed a difference. The recorded curves for $\epsilon^{\prime \prime}$, the loss index, are shown in Figure 2.

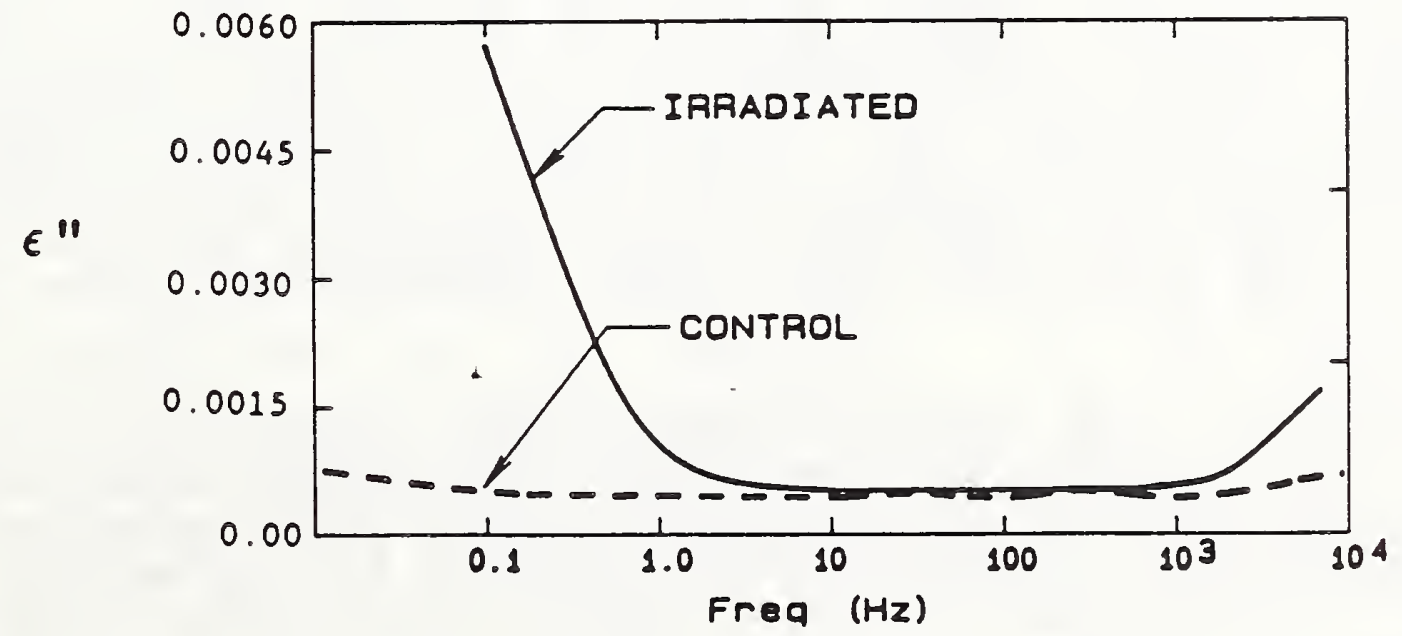

Figure 2. TDS Measurements on naturally aged cable samples 
For the irradiated cable, there is a clear, rapid increase in $\epsilon$ " at frequencies below $1 \mathrm{~Hz}$. The increase is so large that it is ten times larger at $0.01 \mathrm{~Hz}$ than the range used to display the three results. This increase is due mainly to the presence of a dc conductivity that is not present in the unirradiated cables. In contrast, the two different, unirradiated cables show a low, relatively constant $\epsilon "$ with no evidence of a dc conductivity. While there are small, differences between the two samples, these are clearly distinguished from the larger effects of radiation.

TDS measurements on artificially aged specimens

Six samples of cross-linked polyolefin insulation were supplied by Sandia National Laboratories, where accelerated aging tests are under investigation. They were of the type used for low-voltage power applications and were supplied as tubes $10 \mathrm{~cm}$ long with the 12 AWG center conductor missing. The inner diameter was $0.23 \mathrm{~cm}$ and the outer diameter was $0.39 \mathrm{~cm}$. The tubes came in three colors: red, white and black. One set was in the original, unaged state while the other set had been aged at Sandia for 16 days at $120^{\circ} \mathrm{C}$ followed by 16 days exposure at $65 \mathrm{krad} / \mathrm{h}$, for a total dose of $25 \mathrm{Mrad}$. The samples were prepared for measurement by reinserting a center conductor and applying a conductive layer to the outside surface so that a cylindrical capacitor was obtained. The capacitance and loss were measured between the central conductor and the guarded, outer electrode.

The results for the three different color samples are given in Figure 3 which shows the loss component as a function of frequency measured at $50^{\circ} \mathrm{C}$. At $10 \mathrm{kHz}$, the measured capacitance was $15 \mathrm{pF}$, corresponding to a dielectric constant of 2.4. This result should be contrasted to polyethylene which has a dielectric constant of 2.1 .

If one considers the unaged samples, the high dielectric constant indicates that these samples contain not only colorant, left over cross-linking agent residues, and the normal additives, but also an inorganic filler. The high loss at low frequencies also suggest the presence of a filler as the loss seems to be related to an ionic conduction mechanism. It should also be noted that the colorant did seem to create small but systematic differences between the samples.

Upon aging with radiation, a great reduction is apparent in the low-frequency loss. It should be noted that the loss at the lowest frequency for the unaged cables is several times off-scale. This behavior is a complete reversal from the Shippingport polyethylene coaxial cables where the effect of radiation was an increase in the low-frequency loss. However, the loss in these samples after the decrease is still much greater than that of the coaxial cable. This change in conductive loss is a very strong diagnostic feature even though, as noted below, the samples are still at an early stage in the possible service life of this insulation. A less prominent change is the appearance of new relaxations in the irradiated material, especially one centered near $1 \mathrm{~Hz}$, which is apparent only in detailed comparisons of the data, not reported here. While this relaxation is not strong, it is definitely not present in the original material; it could possibly grow with further aging and irradiation and may become important near the end of the service life of the insulation. Only further measurements on more samples can confirm this conjecture.

The changes in dielectric loss spectra do change quite strongly with aging. While the correlations with aging are hard to make from these limited measurements, these changes are much more pronounced than the changes in mechanical properties reported in the Sandia measurements, indicating great potential for the method. However, more samples need to be examined, not only to track further aging in this material, but also to determine the behavior of other insulation systems. At the present stage of the work, no speculation has been made to explain the difference. 


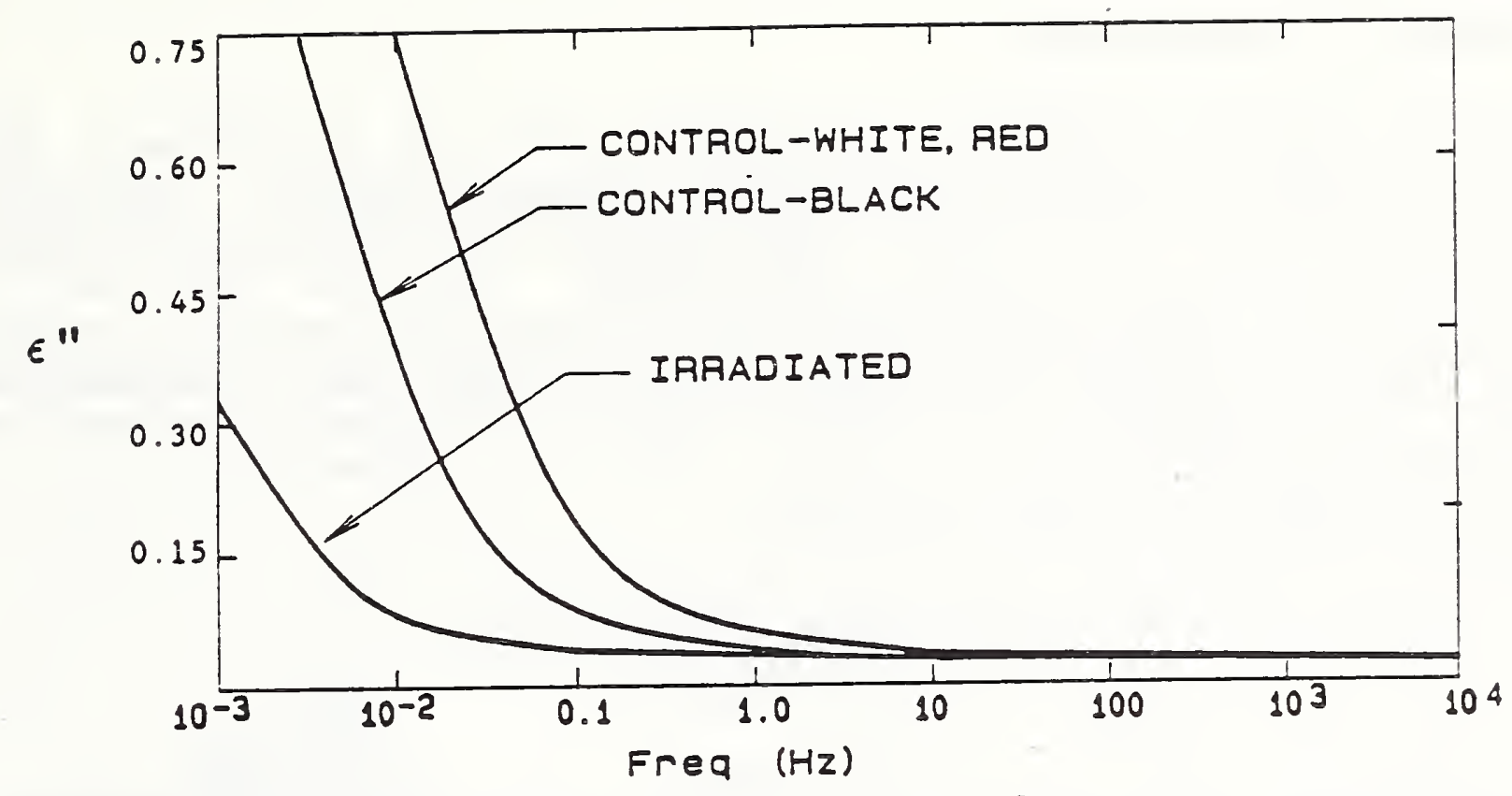

Figure 3. Effect of aging for three samples with different colorants

\section{Developing a data base for TDS correlation}

A commercial version of the Time-Domain Dielectric Spectrometer has just become available, with capabilities fully compatible with the studies reported here. The package consists of a desk-top computer and an instrumentation system contained in a standard instrument rack enclosure. The instrument uses a low-voltage output that is capable of driving loads up to $1000 \mathrm{pF}$.

Since TDS is a nondestructive technique, it can be used on existing cable systems during outage and test times at a plant. Another interesting possibility for application of the TDS measurements is the following: if a specimen of the same material as the cable of interest were placed in the same environment as the cable within the containment, it could be connected to the outside by a pair of wellshielded or impervious cables, and characterized by TDS at any time, without disturbing the power plant operation. Since the TDS test is non-destructive, there would be no limit on the number of tests made on that specimen, from which conclusions could then be drawn on the advancing aging of the adjacent cables. Of course, appropriate temperature balancing would be necessary. From the experience of other aging test plans, there might be a question about introducing additional leads in the containment to provide voltage/current stress on the specimen. Nevertheless, the benefit from such a test plan might outweigh the objections.

The major expectation from a TDS measurement would be to obtain an indication of embrittlement, or other form of degradation leading to reduced cable life. This expectation to quantify aging, to determine margins, and to determine residual life, in turn, will require establishing a correlation between the embrittlement and operaticial quality of the material. This correlation has not yet been developed, but programs conducted by others are aimed at acquiring end-of-life data which could then be correlated with measurements performed with time-domain spectroscopy. Limited initial attempts to interest U.S. utilities in such a cooperative program have not been successful. The EPRI workshop offers an opportunity to propose this program informally to a greater number of utilities. The concept has also been discussed with Electricité de France (EdF) and with Siemens-KWU. We have received some specimens of artificially aged cables from EdF, where the cables received a complete evaluation using the EdF procedures (which do not include TDS at this time). A similar arrangement is under consideration with Siemens-KWU. 
The review of candidate methods, predictably, has not identified a universally acceptable technique for detecting incipient defects (Figure 4). However, at least three interesting possibilities exist: time-domain reflectometry, partial discharge signal processing, and time-domain spectroscopy. The last two will be further investigated at NBS. Other methods have not been actively pursued, pending further development. In particular, the idea of Low Energy Pulse Testing offers some interesting possibility but would require a major development program. The method of stress/strain measurements is currently under development by its inventors, and we are looking forward to further results.

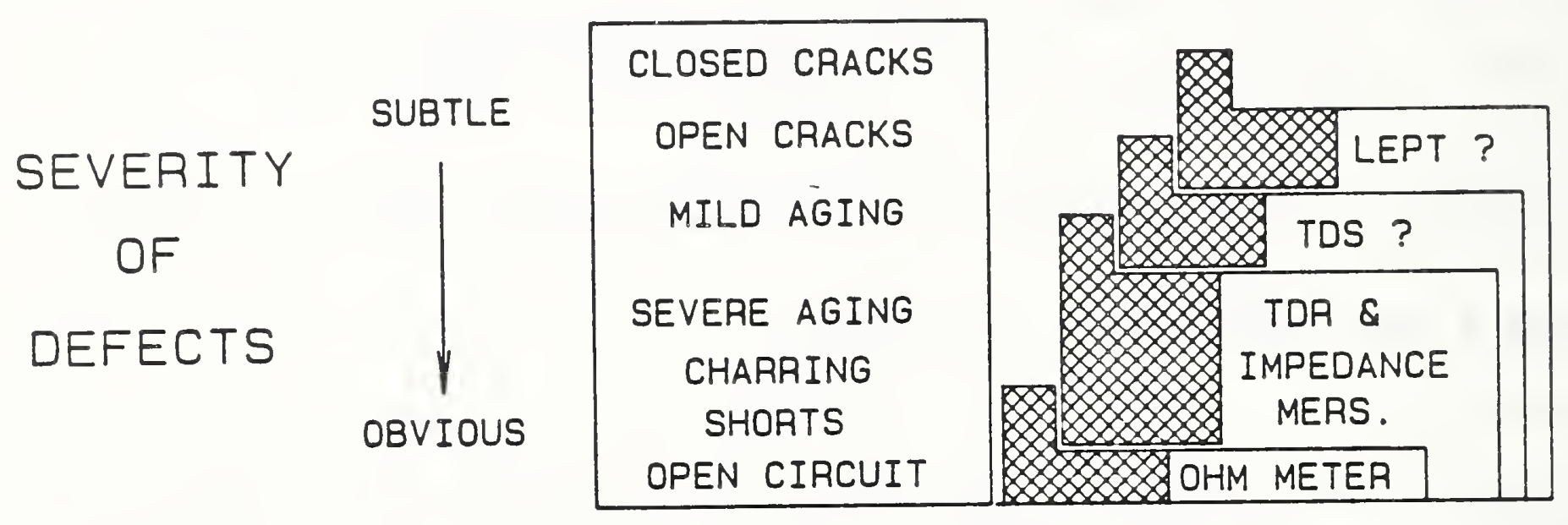

Figure 4. Summary of types of defects and candidate methods

The correlation of partial discharge signals offers an opportunity to extend a technology which has been demonstrated in the laboratory to the more difficult environment of in situ tests at a power plant. A state-of-the-art system will be assembled at NBS, to continue the evaluation toward that type of environment.

Time-domain spectroscopy promises a very powerful detection method for the overall aging of cable insulation. The benefits from the sensitivity of this method, however, cannot be demonstrated until a convincing correlation is established between TDS measurements and insulation integrity. Waiting for the demonstration to be accomplished before joining a cooperative program is a vicious circle. Thus, the goal of this paper, in addition to reporting the NBS work, is to present a strong recommendation for establishing, perhaps through EPRI, a cooperative program for a data base on TDS measurements correlation.

\section{ACKNOWLEDGMENTS}

The evaluation and experiments reported in this paper were conducted by a multidisciplinary team including T.F. Leedy, the authors and with the program guidance and encouragement of J.P. Vora. Review of the program was also provided by B.A. Bell, R.E. Hebner, and K.N. Mathes. The program was supported by funding from the Nuclear Regulatory Commission, Office of Research, under the Nuclear Plant Aging Research (NPAR) Program. 


\section{REFERENCES}

1. Meyer, L.C. "Nuclear Plant-Aging Research on Reactor Protection Systems," NUREG/CR-4740, EGG-2467, October 1986.

2. Dinsel, M.R., Donaldson M.R., and Soberano, F.T. "In Situ Testing of the Shippingport Atomic Power Station Electrical Circuits," NUREG/CR-2956, EGG-2443, April 1987.

3. Meininger, R.D., Soberano, F.T. and Dinsel, M.R. "Three Mile Island Techniques to Detect Degradation in Electrical measurement and Control Circuits," Proceedings International Conference on Nuclear Power Plant Aging, Availability Factor, and Reliability Analysis; San Diego, CA, July $8-12,1985$.

4. Anderson, W.E., Ramboz, J.D., and Ondrejka, A.R. "Final Report: Technical Contributions to the Development of Incipient Fault Detection/Location Instrumentation," NBSIR 86-3392, National Bureau of Standards, April 1986.

5. Weeks, W.L. and Steiner, J.P. "Instrumentation for the Detection and Location of Incipient Faults on Power Cables," IEEE Transactions PAS-104, No. 7, July 1982 .

6. Jenni, A. "Partial Discharge Measurements on Power Cables," Wire Industry, September 1982 .

7. Al-Hussaini, T.J. and Stoner, J.E. "On-going Qualification of Cables in a Pressurized Water Reactor Environment," Proceedings, Nuclear Science Symposium, Orlando, FL, November 1984.

8. Michel, W.0., Siemens-KWU, technical discussion with NBS, December 1987.

9. Toman, G.J. and Gardner, J.B. "Development of a Nondestructive Cable Insulation Test," Proceedings of ANS Meeting on Operability of Nuclear Power Plant Systems in Normal and Adverse Environments, October 1986.

10. Pays, M. and Rey, C., Electricité de France, technical discussion with NBS, December 1987.

11. Mopsik, F.I., "Precision Time-domain Dielectric Spectrometer," Review Scientific Instruments (1984). 
BIBLIOGRAPHIC DATA

SHEET (See instructions)

4. TITLE AND SUBTITLE

A Review of Candidate Methods for Detecting Incipient Defects Due to Aging of Installed Cables in Nuclear Power Plants

5. $A \cup T H O R(S)$

F.I. Mopsik, E.F. Kelley, F.D. Martzloff

6. PERFORMING ORGANIZATION (If joint or other than NBS, see instructions)

NATIONAL BUREAU OF STANDARDS

U.S. DEPARTMENT OF COMMERCE

GAITHERSBURG, MD 20899

9. SPONSORING ORGANIZATION NAME AND COMPLETE ADDRESS (Street. City. Stote. ZIP)

10. SUPPLEMENTARY NOTES

Document describes a computer program; SF-185, FIPS Software Summary, is attached.

11. ABSTRACT (A 200-word or less foctual summary of most significant information. If document includes a significant bibliogrophy or literoture survey. mention it here)

Several types of test methods have been proposed for detecting incipient defects due to aging in cable insulation systems, none offering certainty of detecting all possible types of defects. Some methods apply direct detection of a defect in the cable; other methods detect changes in electrical or non-electrical parameters from which inferences can be drawn on the integrity of the cable. The paper summarizes the first year of a program conducted at the National Bureau of Standards to assess the potential of success for in situ detection of incipient defects by the most promising of these methods.

12. KEY WORDS (Six to twelve entries; alphobetical order: copitalize only proper names: and separate key words by semicolons) cable aging; insulation aging; partial discharge detection; test methods; time-doma in reflectometry; time-domain spectroscopy

\section{AVAILABILITY}

X] Unlimited

$\square$ For Official Distribution. Do Not Release to NTIS

$\square$ Order From Superintendent of Documents, U.S. Government Printing Office, Washington, D.C. 20402.

D Order From National Technical Information Service (NTIS). Springfield, VA. 22161
14. NO. OF PRINTED PAGES 13

15. Price 